\title{
ChemComm
}

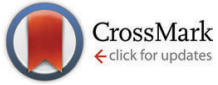

Cite this: Chem. Commun., 2015, 51, 13554

Received 20th May 2015, Accepted 13th July 2015

DOI: $10.1039 / \mathrm{c} 5 \mathrm{cc} 04191 \mathrm{k}$

www.rsc.org/chemcomm

\section{[N-Methyl-2-pyrrolidone][C1-C4 carboxylic acid]: a novel solvent system with exceptional lignin solubility $\dagger$}

\author{
Liwen Mu, ${ }^{a}$ Yijun Shi, ${ }^{b}$ Long Chen, ${ }^{a}$ Tuo Ji, ${ }^{a}$ Ruixia Yuan, ${ }^{\text {ac }}$ Huaiyuan Wang ${ }^{c}$ and \\ Jiahua Zhu*a
}

Novel solvent systems composed of $\mathrm{N}$-methyl-2-pyrrolidone and C1-C4 carboxylic acid exhibit unique physicochemical properties, e.g. large polarity, low viscosity and excellent hydrogen bonding capacity, which have demonstrated excellent lignin solubility that outperforms conventional solvents and ionic liquids.

Technologies for efficient lignocellulosic biomass utilization have significantly advanced over the past few decades. Tremendous research efforts were devoted to cellulose modification for structural fillers in composites, ${ }^{1}$ heavy metal adsorption, ${ }^{2}$ drug delivery, ${ }^{3}$ catalytic conversion into valuable chemicals and fuels, ${ }^{4}$ chemical degradation into small molecules, ${ }^{5}$ etc. Lignin is the second most abundant biopolymer in nature. Due to its complex molecular structure, it remains a challenge to convert lignin into useful chemicals and therefore it is primarily burnt to recover energy in the pulp and paper industry. ${ }^{6}$ The rich aromatic groups in lignin qualify it as a potential resource for valuable aromatic stock chemicals unless it can be depolymerized and converted to desired molecules. A recent review article ${ }^{7}$ has seen the growing interest in lignin utilization over the past few years. To date, the greatest challenges of lignin utilization are (1) hydrophobicity: non-covalent $\pi-\pi$ interaction hinders effective interaction and reactions between lignin and reactants; ${ }^{8}$ (2) indigestibility: a cross-linked structure results in significant chemical resistance towards depolymerization; ${ }^{9}$ (3) complex chemical structure. Also, the pre-treatment process has a significant effect on the chemical characteristics of lignin. ${ }^{10}$ Due to the non-unified structures, it is difficult to develop a general approach to degrade lignin into

\footnotetext{
${ }^{a}$ Intelligent Composites Laboratory, Department of Chemical and Biomolecular Engineering, The University of Akron, Akron, $\mathrm{OH} 44325$, USA. E-mail: jzhu1@uakron.edu; Tel: +1 330 972-6859

${ }^{b}$ Division of Machine Elements, Lulea University of Technology, Lulea, 97187, Sweden

${ }^{c}$ College of Chemistry and Chemical Engineering, Northeast Petroleum University, Daqing 163318, P. R. China

$\dagger$ Electronic supplementary information (ESI) available: Materials, characterization including NMR, FT-IR, TGA, and DSC, and literature summary. See DOI: $10.1039 / \mathrm{c} 5 \mathrm{cc} 04191 \mathrm{k}$
}

desired aromatic compounds. ${ }^{7}$ Moreover, none of these challenges can be addressed unless efficient solvents can be found to dissolve lignin effectively.

Poor solubility of lignin in most existing solvents is a wellknown fact. Aiming to enhance the lignin solubility, various new solvents have been designed and the most effective solvents so far are the ionic liquids (ILs). ILs are defined as salts with a melting temperature less than $100{ }^{\circ} \mathrm{C}$ and are frequently liquid at room temperature. ${ }^{11}$ The lignin solubility in ILs can be tuned by rational design of the anion/cation pairing. The lignin solubility in ILs is affected by three major factors: (1) strong hydrogenbonding anions; ${ }^{12}$ (2) $\pi-\pi$ interactions between aromatic imidazolium IL cations and the aromatic compounds of lignin; ${ }^{13}$ and (3) Brønsted acidic protons. ${ }^{9}$ For example, ILs with a sulfate anion show higher lignin solubility compared to a phosphate anion. ${ }^{14}$ 1-Allyl-3-methylpyrrolidinium chloride exhibits higher solubility than 1-butyl-3-methylpyrrolidinium chloride due to the extended $\pi$-system in the former. ${ }^{13}$ Besides that, solvent viscosity, dissolving temperature and time also play important roles in lignin dissolution. ${ }^{15}$ Even though ILs have demonstrated superior lignin solubility, the major drawbacks of high cost, large viscosity (mostly) and hazardous chemical species especially fluorinated anions greatly restricted their practical applications.

In this work, a new solvent system has been developed by directly mixing $N$-methyl-2-pyrrolidone (NMP) and C1-C4 carboxylic acids (CAs) including formic acid-For, acetic acid-OAc, propionic acid-Pro, oxalic acid-Oxa, malonic acid-Mal and succinic acidSuc (mono-CAs: For, OAc and Pro; di-CAs: Oxa, Mal and Suc), refer to Fig. 1. The physicochemical properties of these solvents are systematically investigated. The lignin dissolution property in these solvents is studied and compared with ILs and traditional solvents. Refer to ESI $\dagger$ S1 for experimental details and characterization.

Solid evidence from Nuclear Magnetic Resonance (NMR) characterization, that is negligible peak shifts of $0.01-0.07 \mathrm{ppm}$ $\left(2 \mathrm{H},-\mathrm{N}-\mathrm{CH}_{2}\right), 0.01-0.06 \mathrm{ppm}\left(2 \mathrm{H}, \mathrm{O}=\mathrm{C}-\mathrm{CH}_{2}\right)$ and $0.01-0.07 \mathrm{ppm}$ $\left(2 \mathrm{H},-\mathrm{CH}_{2}-\right)$ ppm in Fig. S1-S4 (ESI $\left.\dagger\right)$, clearly indicates that proton transfer does not occur in [NMP][CA]. Normally, a significant peak 


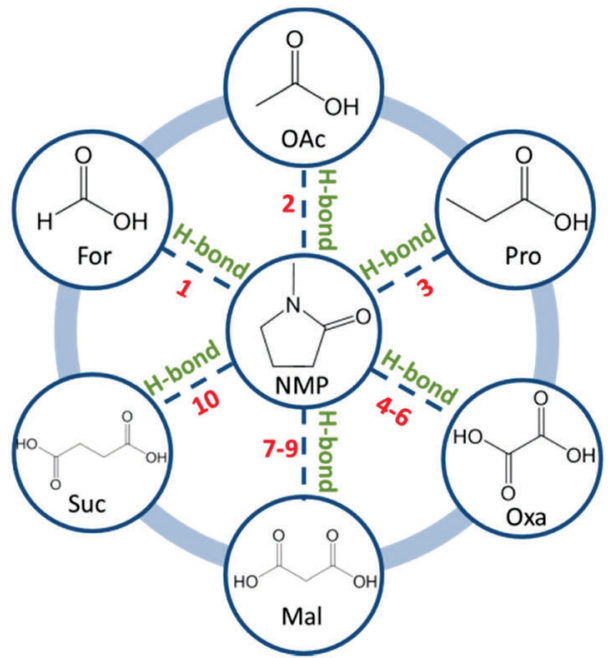

Fig. 1 Molecular structure of NMP and C1-C4 carboxylic acids. Numbers 1-10 indicate solvent composition, refer to Table 1.

shift of $0.2-0.5 \mathrm{ppm}$ will be observed accompanied by proton transfer. ${ }^{16}$ Thus, these solvents cannot be classified as ILs. Considering the weak basicity of NMP and acidity of CAs, H-bond between NMP and CAs will be formed to generate a stable solvent system. The Fourier transform infrared spectroscopy results show that the $-\mathrm{C}=\mathrm{O}$ peaks in both NMP and CAs shift slightly towards lower wavenumbers in all [NMP][CA], Fig. S5-S9 (ESI $\dagger$ ), clearly indicating the $\mathrm{H}$-bond formation between NMP and CAs.

The physical properties and lignin solubility of the solvents are summarized in Table 1. It is obvious that solvent density decreases with increasing carbon numbers for the mono-CAs, which is attributed to the steric hindrance posed by the larger acid groups. ${ }^{17}$ Generally, NMP molecules with di-CAs show relatively higher density compared to the ones with mono-CAs. Apparently, every single di-CA molecule contributes two active sites $(-\mathrm{COOH})$ to form H-bonds with NMP and stronger molecular interaction would be expected. The strong molecular interaction drives the compact packing of molecules and therefore larger density was observed. With increasing [NMP]/[di-CA] molar ratio from 1 to 2 , the solvent density continuously decreases for both [NMP][Oxa] and [NMP][Mal].
Polarity is one of the most important solvent properties, which is defined as the sum of all possible specific and nonspecific intermolecular interactions between the solvent and any potential solute, excluding the interactions leading to chemical transformations of the solute. ${ }^{18}$ The Kamlet-Taft empirical parameters, $\alpha, \beta$, and $\pi^{*}$, were widely used to describe the polarity of solvents including ILs. ${ }^{19}$ The $\alpha$ value describes the ability of a solvent to donate a proton in a solvent-to-solute $\mathrm{H}$-bond, with the fixed reference point of $\alpha=1$ for methanol. ${ }^{20}$ Even though $\alpha$ values of some [NMP][CA] cannot be obtained from the measurement, most of the measurable solvents exhibit large $\alpha$ values, typically close to or larger than 3 . These results indicate that most of these solvents have the capability to donate proton and form hydrogen bonding with lignin. The $\beta$ value describes the solvent's ability to donate electrons to form a $\mathrm{H}$-bond with protons from solute. It seems that $\beta$ values of these solvents distributed in the range of $0.44-0.76$, which is very similar to most of the ILs. ${ }^{21}$ Generally, [NMP] [mono-CA] exhibits a relatively larger $\beta$ value than [NMP][di-CA]. Obviously, the $\beta$ value largely depends on the species of CAs, which is consistent with previous reports in ILs. ${ }^{18 b, 22}$ Moreover, the ratio of [NMP]/ [di-CA] also affects the $\beta$ value. For example, slight variation of the $\beta$ value has been observed in [NMP][Oxa], while $\sim 50 \%$ enhancement has been observed in [NMP][Mal] upon increasing the ratio from 1 to 2 . Over the past few years, there is a continuous debate on the relationship between the $\beta$ value and lignin solubility. Some researchers claim that the $\beta$ value determines lignin solubility ${ }^{23}$ while others claim that the $\beta$ value is not related to it. ${ }^{24}$ Looking at the molecular structure, it is not difficult to see that both proton accepting groups (-O-) and proton donating groups $(-\mathrm{OH})$ widely existed in lignin. That means both donated protons and electrons from solvent may synergistically contribute to the dissolution of lignin, which has been gradually accepted in the area of cellulose solubility. ${ }^{25}$ The lignin solubility is plotted against the $\beta$ value in Fig. 2 . From the linear increasing pattern of lignin solubility with the $\beta$ value of solvent, it is easy to claim the dominating influence of the $\beta$ value. However, the contribution of the protonation effect ( $\alpha$ value) on the lignin molecule by the solvent cannot be simply neglected.

Table 1 Physical properties and lignin solubility of [NMP][CA] solvents

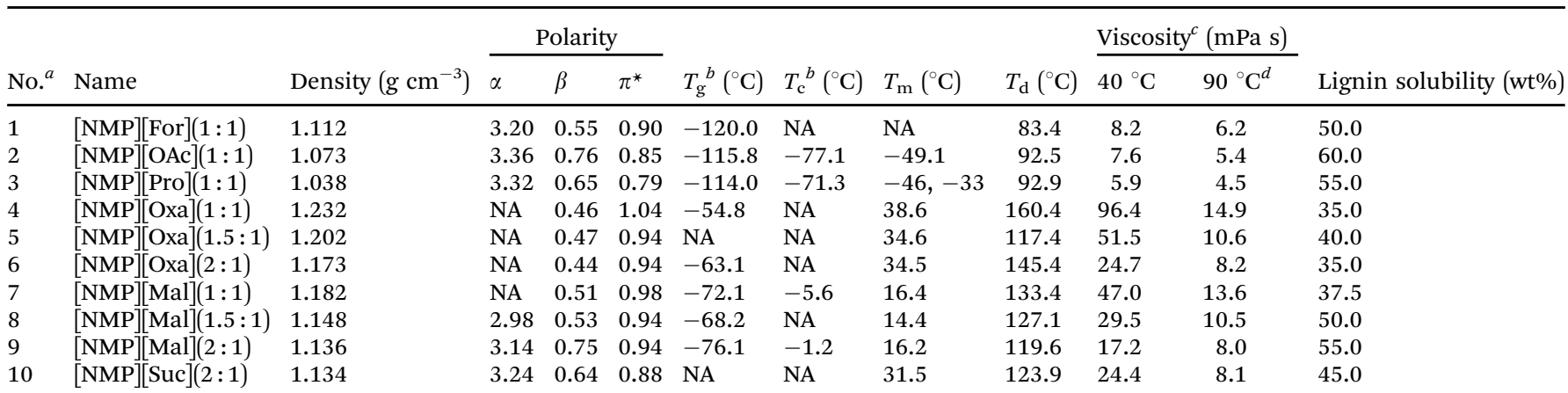

${ }^{a}$ The sample no. corresponding to the specific solvent is used in Fig. 2 and $3 .^{b}$ The glass transition and devitrification peak was not observed for all samples. ${ }^{c}$ The viscosity value is taken at the shear rate of $30 \mathrm{~s}^{-1}$. ${ }^{d}$ The temperature used to dissolve lignin. NA indicates the parameters that are not available from measurement. 


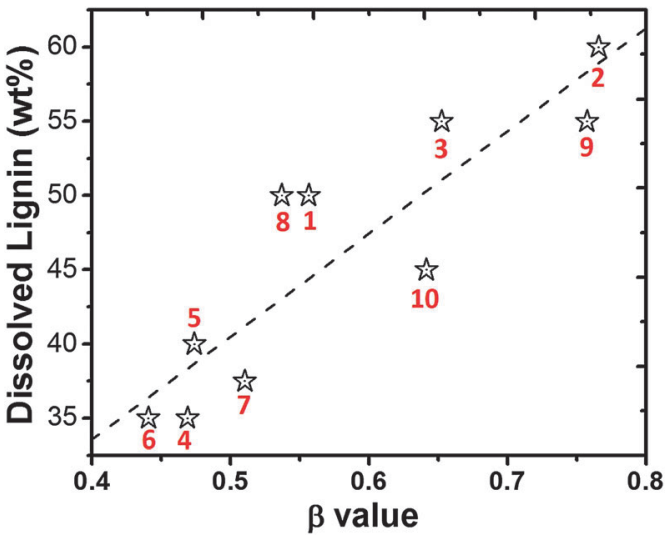

Fig. 2 Relationship of lignin solubility and $\beta$ values of [NMP][CA] solvents $(1-10)$. The dashed line is linearly fitted from the 10 data points.

In addition to the $\alpha$ and $\beta$ values of the solvents, solvent viscosity is another important factor that greatly affects the solubility of solute. ${ }^{26}$ In Table 1 , solvents 2 and 9 have similar $\beta$ values, however, higher lignin solubility has been observed in 2 (60.0 wt\%) than $9(55.0 \mathrm{wt} \%)$ due to its relatively lower viscosity. Similarly, even though solvent 9 exhibits a higher $\beta$ value than 3 , the same lignin solubility was observed because of its higher viscosity. Evidence from solvents 4, 6, and 7 gives the same conclusion. One of the major disadvantages of using ILs in dissolution, mixing and separation processes is their intrinsic high viscosity (typically within $0.1-2$ Pa $\mathrm{s}$, that is $1-3$ orders of magnitude higher than conventional organic solvents), which poses great challenges in achieving process efficiency. ${ }^{27}$ The lower viscosity of these new solvents $\left(4.5-96.0 \times 10^{-3} \mathrm{~Pa} \mathrm{~s}\right)$ provides great advantages in material processing and process efficiency. The glass transition $\left(T_{\mathrm{g}}\right)$, devitrification $\left(T_{\mathrm{c}}\right)$, melting $\left(T_{\mathrm{m}}\right)$ and degradation $\left(T_{\mathrm{d}}\right)$ temperatures of all these solvents are summarized in Table 1 . The corresponding TGA and DSC curves of these solvents are provided in ESI, $\uparrow$ Fig. S10 and S11.

The lignin solubility in these new solvents has been compared with a wide range of ILs, ${ }^{12,16 b, 24,28}$ and traditional solvents, ${ }^{29}$ Fig. 3. Certainly, the lignin solubility depends on many factors, such as dissolving temperature, time, stirring method and lignin source. Fig. 3 uses the reported maximum lignin solubility regardless of the

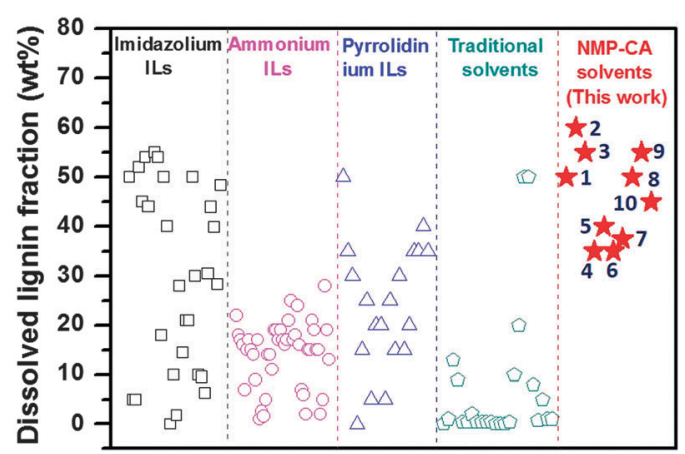

Fig. 3 Comparison of lignin solubility in [NMP][CA] solvents (1-10) with literature reported ionic liquids and traditional solvents. For detailed information on the reported values refer to ESI $\dagger$ Table S1. dissolution conditions. For more details refer to Table S1 in the ESI. $\dagger$ Obviously, ILs exhibit much higher lignin solubility than traditional solvents. Some of the imidazolium and pyrrolidinium based ILs reach 30-55.0 wt\% solubility, which are significantly higher than ammonium based ILs of below $30.0 \mathrm{wt} \%$. The [NMP $][\mathrm{CA}]$ in this work shows even higher lignin solubility of 35.0-60.0 wt\%, while a single NMP or CA only dissolves $1-5 \%$ lignin, Table S1 (ESI $\dagger$ ). Some of the [NMP][CA] solvents also exhibit higher lignin solubility than pyrrolidium (Pyrr) ILs including [Pyrr][For], [Pyrr][OAc] and [Pyrr][Pro] (40-45\%, Table S1, ESI $\dagger$ ). The large solubility of lignin in [NMP][CA] is majorly attributed to the following beneficial factors: (1) high density H-bonding between lignin and [NMP][CA]. Besides the capability of proton donation from $-\mathrm{COOH}$ (in $\mathrm{CA}$ ) to lignin, $-\mathrm{C}=\mathrm{O}$ in NMP is also able to accept protons at the oxygen center from lignin (-OH or aldehyde groups). These reciprocal interactions between [NMP $][\mathrm{CA}]$ and lignin ensure higher H-bond density than other solvents and therefore large solubility was observed; (2) low viscosity. Low viscous solvent ensures an efficient contact between solvent and lignin, which is critically important to breakdown the rigid structure of lignin.

To conclude, we report the synthesis of a series of novel solvents with NMP and mono/di-carboxylic acids. These solvents show unique physicochemical properties such as high polarity, low viscosity, excellent thermal stability and large lignin solubility. Large $\alpha$ and $\beta$ values and low viscosity of these new solvents synergistically contribute to the large lignin solubility. Comparing with ILs and other traditional solvents, these new solvents have the greatest advantages of low cost, widely accessible resources, easy preparation as well as efficient processing in dissolving lignin.

This work was financially supported by the start-up fund of The University of Akron. Partial support from Faculty Research Committee, Biomimicry Research Incentive Center and Firestone Faculty Research Fellowship from The University of Akron is also acknowledged.

\section{Notes and references}

1 J. Yang, J. J. Zhao and X. M. Zhang, Cellulose, 2014, 21, 3487.

2 (a) D. W. O'Connell, C. Birkinshaw and T. F. O'Dwyer, Bioresour. Technol., 2008, 99, 6709; (b) N. Isobe, X. Chen, U.-J. Kim, S. Kimura, M. Wada, T. Saito and A. Isogai, J. Hazard. Mater., 2013, 260, 195.

3 S. Akhlaghi, R. Berry and K. Tam, Cellulose, 2013, 20, 1747.

4 (a) B. O. d. Beeck, M. Dusselier, J. Geboers, J. Holsbeek, E. Morré, S. Oswald, L. Giebeler and B. F. Sels, Energy Environ. Sci., 2015, 8, 230; $(b)$ J. Han, S. M. Sen, D. M. Alonso, J. A. Dumesic and C. T. Maravelias, Green Chem., 2014, 16, 653.

5 (a) L. Zhou, Y. He, Z. Ma, R. Liang, T. Wu and Y. Wu, Carbohydr. Polym., 2015, 117, 694; (b) E. J. Cho, S. Jung, H. J. Kim, Y. G. Lee, K. C. Nam, H.-J. Lee and H.-J. Bae, Chem. Commun., 2012, 48, 886.

6 A. Rahimi, A. Ulbrich, J. J. Coon and S. S. Stahl, Nature, 2014, 515, 249.

7 C. Xu, R. A. D. Arancon, J. Labidi and R. Luque, Chem. Soc. Rev., 2014, 43, 7485.

8 J. Zakzeski, P. C. A. Bruijnincx, A. L. Jongerius and B. M. Weckhuysen, Chem. Rev., 2010, 110, 3552.

9 M. M. Hossain and L. Aldous, Aust. J. Chem., 2012, 65, 1465.

10 H. Lange, S. Decina and C. Crestini, Eur. Polym. J., 2013, 49, 1151.

11 A. Pinkert, K. N. Marsh, S. Pang and M. P. Staiger, Chem. Rev., 2009, 109, 6712 .

12 Y. Pu, N. Jiang and A. J. Ragauskas, J. Wood Chem. Technol., 2007, $27,23$. 
13 M. Zavrel, D. Bross, M. Funke, J. Buechs and A. C. Spiess, Bioresour. Technol., 2009, 100, 2580.

14 A. George, K. Tran, T. J. Morgan, P. I. Benke, C. Berrueco, E. Lorente, B. C. Wu and J. D. Keasling, Green Chem., 2011, 13, 3375.

15 A. Diop, A. H. Bouazza, C. Daneault and D. Montplaisir, BioResources, 2013, 8, 4270.

16 (a) D. R. MacFarlane, J. M. Pringle, K. M. Johansson, S. A. Forsyth and M. Forsyth, Chem. Commun., 2006, 1905; (b) E. C. Achinivu, R. M. Howard, G. Li, H. Gracz and W. A. Henderson, Green Chem., 2014, 16, 1114.

17 Z. Wang, L. Fu, H. Xu, Y. Shang, L. Zhang and J. Zhang, J. Chem. Eng. Data, 2012, 57, 1057.

18 (a) C. Reichardt and T. Welton, Solvents and Solvent Effects in Organic Chemistry, Wiley-VCH Verlag GmbH \& Co. KGaA, 2010, pp. 425-508; (b) M. A. Ab Rani, A. Brant, L. Crowhurst, A. Dolan, M. Lui, N. H. Hassan, J. P. Hallett, P. A. Hunt, H. Niedermeyer, J. M. Perez-Arlandis, M. Schrems, T. Welton and R. Wilding, Phys. Chem. Chem. Phys., 2011, 13, 16831.

19 (a) A. Schade, N. Behme and S. Spange, Chem. - Eur. J., 2014, 20, 2232; (b) N. Sun, R. Parthasarathi, A. M. Socha, J. Shi, S. Zhang, V. Stavila, K. L. Sale, B. A. Simmons and S. Singh, Green Chem., 2014, 16, 2546; (c) A. P. Abbott, E. G. Hope, R. Mistry and A. M. Stuart, Green Chem., 2009, 11, 1530.

20 R. W. Taft and M. J. Kamlet, J. Am. Chem. Soc., 1976, 98, 2886.

21 (a) C. Chiappe, C. S. Pomelli and S. Rajamani, J. Phys. Chem. B, 2011, 115, 9653; (b) J. N. Canongia Lopes, M. F. C. Gomes, P. Husson,
A. A. H. Padua, L. P. N. Rebelo, S. Sarraute and M. Tariq, J. Phys. Chem. B, 2011, 115, 6088.

22 (a) A. Xu, J. Wang and H. Wang, Green Chem., 2010, 12, 268; (b) Y. Wu, T. Sasaki, K. Kazushi, T. Seo and K. Sakurai, J. Phys. Chem. B, 2008, 112, 7530.

23 T. V. Doherty, M. Mora-Pale, S. E. Foley, R. J. Linhardt and J. S. Dordick, Green Chem., 2010, 12, 1967.

24 W. E. S. Hart, J. B. Harper and L. Aldous, Green Chem., 2015, 17, 214. 25 B. Lu, A. Xu and J. Wang, Green Chem., 2014, 16, 1326.

26 S. Fendt, S. Padmanabhan, H. W. Blanch and J. M. Prausnitz, J. Chem. Eng. Data, 2011, 56, 31.

27 S. Zhang, N. Sun, X. He, X. Lu and X. Zhang, J. Chem. Eng. Data, 2006, 35, 1475.

28 (a) S. H. Lee, T. V. Doherty, R. J. Linhardt and J. S. Dordick, Biotechnol. Bioeng., 2009, 102, 1368; (b) H. Zhao, G. A. Baker and J. V. Cowins, Biotechnol. Prog., 2010, 26, 127; (c) D. Fu, G. Mazza and Y. Tamaki, J. Agric. Food Chem., 2010, 58, 2915; (d) H. Lateef, S. Grimes, P. Kewcharoenwong and B. Feinberg, J. Chem. Technol. Biotechnol., 2009, 84, 1818; (e) Y. Wang, L. Wei, K. Li, Y. Ma, N. Ma, S. Ding, L. Wang, D. Zhao, B. Yan, W. Wan, Q. Zhang, X. Wang, J. Wang and H. Li, Bioresour. Technol., 2014, 170, 499; ( $f$ ) Q.-P. Liu, X.-D. Hou, N. Li and M.-H. Zong, Green Chem., 2012, 14, 304; (g) X.-D. Hou, J. Xu, N. Li and M.-H. Zong, Biotechnol. Bioeng., 2015, 112, 65; (h) Y. Hamada, K. Yoshida, R.-i. Asai, S. Hayase, T. Nokami, S. Izumi and T. Itoh, Green Chem., 2013, 15, 1863.

29 N. Sun, H. Rodriguez, M. Rahman and R. D. Rogers, Chem. Commun., 2011, 47, 1405. 